\title{
Chronic granulomatous disease: why an inflammatory disease?
}

\author{
P. Roxo-Junior ${ }^{1}$ and H.M.L. Simão ${ }^{2}$ \\ ${ }^{1}$ Departamento de Pediatria, Faculdade de Medicina de Ribeirão Preto, \\ Universidade de São Paulo, Ribeirão Preto, SP, Brasil \\ ${ }^{2}$ Departamento de Biologia e Farmácia, Faculdade de Medicina de Santa Cruz, \\ Universidade de Santa Cruz do Sul, Santa Cruz do Sul, RS, Brasil
}

\begin{abstract}
Chronic granulomatous disease is a primary immunodeficiency caused by mutations in the genes encoding subunits of the phagocytic NADPH oxidase system. Patients can present with severe, recurrent infections and noninfectious conditions. Among the latter, inflammatory manifestations are predominant, especially granulomas and colitis. In this article, we systematically review the possible mechanisms of hyperinflammation in this rare primary immunodeficiency condition and their correlations with clinical aspects.
\end{abstract}

Key words: Chronic granulomatous disease; Inflammation; Infection; Granulomas; NADPH oxidase

\section{Introduction}

Chronic granulomatous disease (CGD) is a fatal primary immunodeficiency caused by mutations in the genes encoding subunits of the NADPH oxidase system, which consists of five subunits. Therefore, this disease has five genetic variants. Mutations in the $C Y B B$ gene are responsible for the $\mathrm{X}$-linked form of the disease that encodes gp91phox, also called NOX2, accounting for two-thirds of CGD cases. Mutations in the other four components account for the remaining one-third of CGD cases and are inherited in an autosomal recessive manner. These are CYBA, encoding p22phox; NCF2, encoding p67phox; NCF1, encoding p47phox; and NCF4, encoding $\mathrm{p} 40$ phox, with the latter being the most recently described (1-6). These defects lead to a failure of phagocytes to catalytically convert oxygen to superoxide and other reactive oxygen species (ROS) that play a key role in killing intracellular pathogens. Usually, patients with X-linked CGD manifest a more severe clinical phenotype with greater morbidity and mortality than patients with autosomal recessive forms (7-9).

The prevalence of CGD at birth has been estimated to be 1 per 120,000-250,000 people (10). CGD patients suffer from early and recurrent severe bacterial and fungal infections (11) that primarily affect the natural barriers of the human body, such as the skin, lymph nodes, and the respiratory tract. Bones and the liver, spleen, and brain can also be affected by infections (12).
The main causes of infections in CGD patients are Staphylococcus aureus, Burkholderia cepacia, Pseudomonas, Serratia marcescens, Aspergillus, and Nocardia species (13). Salmonella sp. are also an important cause of sepsis and mortality and can affect $18 \%$ of CGD patients (14). Olfactomedin 4 (OLFM4) is a neutrophil granule protein that negatively regulates host defenses against bacterial infection. Recently, Liu et al. (15) evaluated the impact of OLFM4 deletion on host defenses against $S$. aureus and Aspergillus fumigatus in a murine gp91phoxdeficiency CGD model. The authors demonstrated that resistance to $S$. aureus sepsis, as well as intracellular killing and in vivo clearance of these bacteria, were significantly increased in gp91phox and OLFM4 double-deficient mice compared with CGD mice. However, the authors did not observe enhanced defenses against $A$. fumigatus in OLFM 4-deficient mice. These results suggest that OLFM4 may be an important tool in CGD patients to increase host defenses against bacterial infection.

\section{Inflammation in CGD}

NADPH oxidase consists of a family of seven members: NOX1, NOX2, NOX3, NOX4, NOX5, DUOX1, and DUOX2 (16). The NADPH oxidase complex 2 is mainly expressed by phagocytes and endothelial cells $(17,18)$. The membrane complex is formed by two

Correspondence: P. Roxo-Junior, Departamento de Pediatria, Faculdade de Medicina de Ribeirão Preto, USP, Avenida Bandeirantes, 3900, 14049-900 Ribeirão Preto, SP, Brasil. Fax: +55-16-3602-2700. E-mail: persiorj@fmrp.com.br 
transmembrane subunits (p22phox and gp91phox, also called NOX2), which are able to couple with the cytosolic subunits (p47phox, p40phox, and p67phox) and small GTPases Rac1 or Rac2. These GTPases are essential for coupling of p67phox to gp91phox, and the subunits p47phox and p40phox are phosphorylated close to gp91phox on the cell membrane when stimulated. This sequence of events allows the transfer of electrons from NADPH to molecular oxygen and produces ROS $(19,20)$. Deficiency of any subunit of NADPH oxidase 2 results in CGD.

Inflammation is frequent in patients with CGD, and in some instances it can be the first clinical manifestation. The disease is so named for the exuberant chronic granuloma formation observed in patients. Current data indicate that either increased or decreased NOX2 activity may lead to inflammatory complications $(21,22)$. The association of increased NOX2 activity with inflammation has been widely discussed. The transcription nuclear factor kappa B (NF-kappa B) controls the expression of several genes involved in the immune-inflammatory response, and is a key activator of innate immunity (23). However, studies evaluating the role of NOX2 in NFkappa B-induced transcription and, consequently, activation or maintenance of the inflammatory response are controversial. Weissmann et al. (24) demonstrated that deficiency of endothelial NOX2, induced by ischemiareperfusion in mice, prevented lung edema. Reinforcing these findings, Gandhirajan et al. (25) showed that NOX2deficient mice had reduced inflammatory release mediators in a model of acute lung injury compared to wild-type controls. On the other hand, some evidence points to a protective role of endothelial NOX2 in lung inflammation. Whitmore et al. (26) used a murine model of sterile generalized inflammation and observed dramatically increased mortality of NOX2-deficient mice compared to wild-type mice. The recruited NOX2-deficient neutrophils demonstrated an enhanced inflammatory phenotype and induced a hemorrhagic inflammatory response in the lungs with rapid and persistent recruitment of neutrophils to the alveolar space.

NADPH oxidase deficiency has been seen predominantly as an immunodeficiency, characterized by an inability to mount an inflammatory response. However, there is current evidence for hyperinflammatory complications of CGD.

The main manifestations are represented prominently by granulomas, as well as colitis, which is frequent and leads to substantial morbidity. Defects of microbicidal activity can facilitate the persistence of pathogens and increase the inflammatory response in some patients $(27,28)$.

Symptomatic disease can include colitis or enteritis, usually caused by microscopic granulomas, or mechanical obstruction of either the digestive or urinary tract, especially by macroscopic granulomas (29). Research conducted at the National Institutes of Health in the United States showed inflammatory involvement of the gastrointestinal tract in $32.8 \%$ of 140 patients with CGD, $89 \%$ of whom had X-linked inheritance (30). Granuloma formation can affect various organs, with a preference for hollow viscera, such as the colon, stomach, esophagus, and bladder (22).

Granulomas can occur in most instances without an infectious pathogen. This fact can be verified by the absence of microbes inside the lesions and because the lesions often respond to several immunomodulators, such as steroids, cyclosporine A, or azathioprine (22). Nevertheless, the primary mechanism of the increased inflammatory response remains poorly understood.

Nonspecific persistent inflammation is a frequent histopathological finding, and the most commonly described feature is acute and/or chronic inflammation with fibrosis containing noncaseous granulomas. However, the lesions can exhibit particular features in some tissues such as the liver, lymph nodes, and intestinal tract. With active chronic inflammation, one can observe increased numbers of eosinophils, eosinophilic crypt abscesses (intestinal tract), abundant nuclear debris and pigmented macrophages, and a relative paucity of neutrophils (31). This can help differentiate hyperinflammatory manifestations of CGD from other granulomatous diseases like Crohn's disease or tuberculosis (32).

\section{Characteristics and possible mechanisms of inflammation in CGD}

A high production of ROS is usually associated with hyperinflammation. Therefore, the absence or reduction of ROS generation by the NADPH oxidase system leading to enhanced inflammation represents a paradigm shift and requires investigation into underlying mechanisms. It is possible that ROS can modulate the inflammatory response, and the NADPH oxidase system is likely to play an important role in this resolution (22). Some properties of ROS may justify a regulatory action in inflammatory processes, like suppression of proinflammatory mediators, degradation of phagocytosed particles, and impaired survival of proinflammatory cells. The following sections describe possible mechanisms.

\section{NOX2 signaling in myeloid cells}

Disruption of calcium channels. $\mathrm{Ca}^{2+}$ signaling may be impaired in patients with CGD, contributing to hyperinflammation. This can be explained by a more negative membrane potential of CGD granulocytes, which contributes to increased $\mathrm{Ca}^{2+}$ influx and thereby an enhanced inflammatory response (33).

Impaired intracellular signaling and an imbalance of inflammatory mediators. The absence of ROS in CGD leukocytes creates signaling alterations that favor 
proinflammatory responses. This can be explained by ROS involvement in the regulation of intracellular signaling, especially the oxidation of cysteine residues in phosphatases and transcription factors (34). CGD phagocytes produce high levels of tumor necrosis factor-alpha and interleukin (IL)-8, probably through hyperactivation of NF-kappa $\mathrm{B}$, contributing to the inflammatory response $(33,35)$. Moreover, there is some evidence that NOX2 deficiency can reduce the activation of indoleamine dioxygenase, leading to higher gammadelta $\mathrm{T}$ cell activity and IL-17 production (3). Myeloidrelated proteins (MRP), also called S100A8 (MRP8) and S100A9 (MRP14), are two calcium-binding proteins linked to innate immunity, and they are expressed in neutrophils and monocytes. One of their main functions is to favor NADPH oxidase activation. Therefore, these proteins are important mediators of inflammatory disease (36). On the other hand, the production of anti-inflammatory mediators such as IL-10, transforming growth factor beta (TGF- $\beta$ ), and prostaglandin 2 by human CGD phagocytes is usually low (37).

It seems that CGD phagocytes are unable to inactivate inflammatory mediators. The catabolism of leukotrienes and $\mathrm{S} 100$ proteins is ROS production dependent in vitro (38).

Abnormal apoptosis. There is evidence suggesting that ROS can induce neutrophil apoptosis. Apoptosis of inflammatory cells represents an important physiological mechanism to avoid hyperinflammation and secondary necrosis (22). Apoptotic cells expose phosphatidyl serines (PS), which can be recognized by PS receptors in macrophages, allowing the uptake of the apoptotic cells (39). This process leads to TGF- $\beta$ production by the macrophages, promoting control of inflammation (40). There is evidence that human and murine CGD neutrophils have diminished/delayed PS exposure. The failure to ingest apoptotic cells is hypothesized to cause immunization to self-antigens, leading, for example, to a higher prevalence of lupus in CGD patients $(3,41)$. However, impaired phagocytosis of apoptotic cells by macrophages can be reversed by interferon-gamma in a nitric oxide-dependent manner (42).

Dysregulation of toll-like-receptor (TLR) expression. The expression of some TLRs, like TLR-5 and TLR-9, can be low in CGD patient neutrophils. This can contribute to impaired pathogen recognition, phagocytosis, and chemotaxis, leading to increased disease severity. On the other hand, some innate immune receptors, such as

\section{References}

1. Roos D, Kuhns DB, Maddalena A, Bustamante J, Kannengiesser C, de Boer M, et al. Hematologically important mutations: the autosomal recessive forms of chronic granulomatous disease (second update). Blood Cells Mol Dis 2010; 44: 291-299, doi: 10.1016/j.bcmd.2010.01.009.
CD35, can be upregulated, which might be linked to the increased frequency of autoimmune diseases (43).

\section{Reduced degradation of phagocytosed particles or apoptotic cells}

A deficiency in the NADPH oxidase system in CGD patient phagocytes leads to reduced degradation of phagocytosed material or apoptotic cells, which implicates either the remaining phagocytosed pathogen or apoptotic neutrophils phagocytosed by macrophages, such as pathognomonic eosinophilic crystals. The main consequence is a persistent activation and hyperinflammation at the cellular level (44).

\section{Genetic polymorphisms}

The trend to develop granulomatous complications in CGD patients appears to be influenced by genetic modifiers, as demonstrated by Foster et al. (45). The authors studied a cohort of 129 CGD patients, and 7 candidate genes, each containing a physiologically relevant polymorphism predicted to influence the host inflammatory response, were selected for analysis. Patients with genotypes associated with myeloperoxidase, Fc $\gamma$ RIIIb, and Fc $\gamma$ RIla receptors had the highest risk for chronic gastrointestinal complications. Thus, subtle genetic differences in molecules of innate immunity seem to contribute to specific inflammatory responses in CGD patients.

\section{Final considerations}

It seems that the amount of ROS generated by neutrophils varies considerably from one individual to the other, and this can be dependent on genetic variations and other factors, such as nutritional uptake of prooxidants and antioxidants, oxygen tension in a given tissue, and the hormonal and cytokine environment (46-48).

CGD patients usually exhibit a ROS ${ }^{\text {low }}$ inflammatory response, characterized by a strong activation of oxygenindependent killing mechanisms and an increase in neutrophil influx. This kind of response tends to cause more tissue damage and is inefficient in removing phagocytized material, as evidenced by pigmented macrophages. In addition, this kind of response can be associated with autoimmune disease, as is often observed in CGD patients.

2. Roos D, Kuhns DB, Maddalena A, Roesler J, Lopez JA, Ariga T, et al. Hematologically important mutations: X-linked chronic granulomatous disease (third update). Blood Cells Mol Dis 2010; 45: 246-265, doi: 10.1016/j.bcmd 2010.07.012. 
3. Rieber N, Hector A, Kuijpers T, Roos D, Hartl D. Current concepts of hyperinflammation in chronic granulomatous disease. Clin Dev Immunol 2012; 2012: 252-460, doi: $10.1155 / 2012 / 252460$.

4. Jakobsen MA, Katzenstein TL, Valerius NH, Roos D, Fisker $\mathrm{N}$, Mogensen $\mathrm{TH}$, et al. Genetical analysis of all Danish patients diagnosed with chronic granulomatous disease. Scand J Immunol 2012; 76: 505-511, doi: 10.1111/j.13653083.2012.02771.x.

5. Heyworth PG, Curnutte JT, Rae J, Noack D, Roos D, van Koppen E, et al. Hematologically important mutations: Xlinked chronic granulomatous disease (second update). Blood Cells Mol Dis 2001; 27: 16-26, doi: 10.1006/bcmd. 2000.0347.

6. Ahlin A, De Boer M, Roos D, Leusen J, Smith Cl, Sundin U, et al. Prevalence, genetics and clinical presentation of chronic granulomatous disease in Sweden. Acta Paediatr 1995; 84: 1386-1394, doi: 10.1111/j.1651-2227.1995.tb13575.x.

7. Chaplin DD. Overview of the immune response. J Allergy Clin Immunol 2010; 125: S3-S23, doi: 10.1016/j.jaci. 2009.12.980.

8. Desjardins $\mathrm{A}$, Coignard-Biehler $\mathrm{H}$, Mahlaoui $\mathrm{N}$, Frange $\mathrm{P}$, Bougnoux ME, Blanche $S$, et al. [Chronic granulomatous disease: pathogenesis and therapy of associated fungal infections]. Med Sci 2012; 28: 963-969.

9. Alsultan A, Williams MS, Lubner S, Goldman FD. Chronic granulomatous disease presenting with disseminated intracranial aspergillosis. Pediatr Blood Cancer 2006; 47: 107110, doi: $10.1002 / p b c .20426$.

10. Seger RA. Chronic granulomatous disease: recent advances in pathophysiology and treatment. Neth $\mathrm{J}$ Med 2010; 68: 334-340.

11. Ben-Ari J, Wolach O, Gavrieli R, Wolach B. Infections associated with chronic granulomatous disease: linking genetics to phenotypic expression. Expert Rev Anti Infect Ther 2012; 10: 881-894, doi: 10.1586/eri.12.77.

12. de Oliveira-Junior EB, Prando C, Lopez JA, Arango JC, Buzolin M, Rehder $\mathrm{J}$, et al. High-performance liquid chromatography under partially denaturing conditions (dHPLC) is a fast and cost-effective method for screening molecular defects: four novel mutations found in X-linked chronic granulomatous disease. Scand J Immunol 2012; 76: 158-166, doi: 10.1111/j.1365-3083.2012.02714.x.

13. Roxo P Jr, de Menezes UP, Condino-Neto A, Ferriani VP, Takayanagui OM. Unusual presentation of brain aspergillosis in chronic granulomatous disease. Pediatr Neurol 2010; 43: 442-444, doi: 10.1016/j.pediatrneurol.2010.06.020.

14. Winkelstein JA, Marino MC, Johnston RB Jr, Boyle J, Curnutte J, Gallin Jl, et al. Chronic granulomatous disease. Report on a national registry of 368 patients. Medicine 2000; 79: 155-169, doi: 10.1097/00005792-200005000-00003.

15. Liu W, Yan M, Sugui JA, Li H, Xu C, Joo J, et al. Olfm4 deletion enhances defense against Staphylococcus aureus in chronic granulomatous disease. J Clin Invest 2013; 123 : 3751-3755, doi: 10.1172/JCI68453.

16. Lambeth JD. NOX enzymes and the biology of reactive oxygen. Nat Rev Immunol 2004; 4: 181-189, doi: 10.1038/ nri1312.

17. Babior BM. The NADPH oxidase of endothelial cells. IUBMB Life 2000; 50: 267-269, doi: 10.1080/15216540051080976.

18. Babior BM. NADPH oxidase. Curr Opin Immunol 2004; 16 :
42-47, doi: 10.1016/j.coi.2003.12.001.

19. El-Benna J, Dang PM, Gougerot-Pocidalo MA. Priming of the neutrophil NADPH oxidase activation: role of p47phox phosphorylation and NOX2 mobilization to the plasma membrane. Semin Immunopathol 2008; 30: 279-289, doi: 10.1007/s00281-008-0118-3.

20. Chessa TA, Anderson KE, Hu Y, Xu Q, Rausch O, Stephens LR, et al. Phosphorylation of threonine 154 in p40phox is an important physiological signal for activation of the neutrophil NADPH oxidase. Blood 2010; 116: 60276036, doi: 10.1182/blood-2010-08-300889.

21. Lambeth JD. Nox enzymes, ROS, and chronic disease: an example of antagonistic pleiotropy. Free Radic Biol Med 2007; 43: 332-347, doi: 10.1016/j.freeradbiomed. 2007.03.027.

22. Schappi MG, Jaquet $V$, Belli DC, Krause $\mathrm{KH}$. Hyperinflammation in chronic granulomatous disease and anti-inflammatory role of the phagocyte NADPH oxidase. Semin Immunopathol 2008; 30: 255-271, doi: 10.1007/ s00281-008-0119-2.

23. Ghosh S, Hayden MS. New regulators of NF-kappaB in inflammation. Nat Rev Immunol 2008; 8: 837-848, doi: 10.1038/nri2423.

24. Weissmann N, Sydykov A, Kalwa H, Storch U, Fuchs B, Schnitzler M, et al. Activation of TRPC6 channels is essential for lung ischaemia-reperfusion induced oedema in mice. Nat Commun 2012; 3: 649, doi: 10.1038/ ncomms 1660.

25. Gandhirajan RK, Meng S, Chandramoorthy HC, Mallilankaraman K, Mancarella S, Gao H, et al. Blockade of NOX2 and STIM1 signaling limits lipopolysaccharideinduced vascular inflammation. J Clin Invest 2013; 123: 887-902.

26. Whitmore LC, Hilkin BM, Goss KL, Wahle EM, Colaizy TT, Boggiatto PM, et al. NOX2 protects against prolonged inflammation, lung injury, and mortality following systemic insults. J Innate Immun 2013; 5: 565-580, doi: 10.1159/ 000347212.

27. Notarangelo LD. Primary immunodeficiencies. J Allergy Clin Immunol 2010; 125: S182-S194, doi: 10.1016/j.jaci. 2009.07.053.

28. von Rosenvinge EC, O'Donnell TG, Holland SM, Heller T. Chronic granulomatous disease. Inflamm Bowel Dis 2010; 16: 9, doi: 10.1002/ibd.20912.

29. Marciano BE, Rosenzweig SD, Kleiner DE, Anderson VL, Darnell DN, Anaya-O'Brien S, et al. Gastrointestinal involvement in chronic granulomatous disease. Pediatrics 2004; 114: 462-468, doi: 10.1542/peds.114.2.462.

30. Dinauer MC. Chronic granulomatous disease and other disorders of phagocyte function. Hematology Am Soc Hematol Educ Program 2005; 89-95, doi: 10.1182/ashedu cation-2005.1.89.

31. Schappi MG, Klein NJ, Lindley KJ, Rampling D, Smith VV, Goldblatt D, et al. The nature of colitis in chronic granulomatous disease. J Pediatr Gastroenterol Nutr 2003; 36: 623-631, doi: 10.1097/00005176-20030500000006 .

32. LeVine S, Smith VV, Malone M, Sebire NJ. Histopathological features of chronic granulomatous disease (CGD) in childhood. Histopathology 2005; 47: 508516, doi: 10.1111/j.1365-2559.2005.02258.x. 
33. Geiszt M, Kapus A, Nemet K, Farkas L, Ligeti E. Regulation of capacitative $\mathrm{Ca}^{2+}$ influx in human neutrophil granulocytes. Alterations in chronic granulomatous disease. J Biol Chem 1997; 272: 26471-26478, doi: 10.1074/jbc. 272.42.26471.

34. Bedard K, Krause KH. The NOX family of ROS-generating NADPH oxidases: physiology and pathophysiology. Physiol Rev 2007; 87: 245-313, doi: 10.1152/physrev.00044.2005.

35. Deng J, Wang X, Qian F, Vogel S, Xiao L, Ranjan R, et al. Protective role of reactive oxygen species in endotoxininduced lung inflammation through modulation of IL-10 expression. J Immunol 2012; 188: 5734-5740, doi: 10.4049/ jimmunol.1101323.

36. Berthier S, Nguyen MV, Baillet A, Hograindleur MA, Paclet $\mathrm{MH}$, Polack B, et al. Molecular interface of S100A8 with cytochrome b558 and NADPH oxidase activation. PLoS One 2012; 7: e40277, doi: 10.1371/journal.pone.0040277.

37. Brown JR, Goldblatt D, Buddle J, Morton L, Thrasher AJ. Diminished production of anti-inflammatory mediators during neutrophil apoptosis and macrophage phagocytosis in chronic granulomatous disease (CGD). J Leukoc Biol 2003; 73: 591-599, doi: 10.1189/jlb.1202599.

38. Harrison CA, Raftery MJ, Walsh J, Alewood P, lismaa SE, Thliveris $S$, et al. Oxidation regulates the inflammatory properties of the murine S100 protein S100A8. J Biol Chem 1999; 274: 8561-8569, doi: 10.1074/jbc.274.13.8561.

39. Henson PM, Hume DA. Apoptotic cell removal in development and tissue homeostasis. Trends Immunol 2006; 27: 244-250, doi: 10.1016/j.it.2006.03.005.

40. Henson PM. Dampening inflammation. Nat Immunol 2005; 6: 1179-1181, doi: 10.1038/ni1205-1179.

41. Sanford AN, Suriano AR, Herche D, Dietzmann K, Sullivan $\mathrm{KE}$. Abnormal apoptosis in chronic granulomatous disease and autoantibody production characteristic of lupus.
Rheumatology 2006; 45: 178-181, doi: 10.1093/rheumatology/ kei135.

42. Fernandez-Boyanapalli R, McPhillips KA, Frasch SC Janssen WJ, Dinauer MC, Riches DW, et al. Impaired phagocytosis of apoptotic cells by macrophages in chronic granulomatous disease is reversed by IFN-gamma in a nitric oxide-dependent manner. J Immunol 2010; 185: 4030-4041, doi: 10.4049/jimmunol.1001778.

43. Hartl D, Lehmann N, Hoffmann F, Jansson A, Hector A Notheis $\mathrm{G}$, et al. Dysregulation of innate immune receptors on neutrophils in chronic granulomatous disease. J Allergy Clin Immunol 2008; 121: 375-382, doi: 10.1016/j.jaci. 2007.10.037.

44. Schappi M, Deffert C, Fiette L, Gavazzi G, Herrmann F, Belli $D$, et al. Branched fungal beta-glucan causes hyperinflammation and necrosis in phagocyte NADPH oxidase-deficient mice. J Pathol 2008; 214: 434-444, doi: 10.1002/path.2298.

45. Foster CB, Lehrnbecher T, Mol F, Steinberg SM, Venzon DJ, Walsh TJ, et al. Host defense molecule polymorphisms influence the risk for immune-mediated complications in chronic granulomatous disease. J Clin Invest 1998; 102: 2146-2155, doi: 10.1172/JCI5084.

46. Holmes B, Page AR, Good RA. Studies of the metabolic activity of leukocytes from patients with a genetic abnormality of phagocytic function. J Clin Invest 1967; 46: 14221432, doi: $10.1172 / \mathrm{JCl} 105634$

47. Holmes B, Quie PG, Windhorst DB, Good RA. Fatal granulomatous disease of childhood. An inborn abnormality of phagocytic function. Lancet 1966; 1: 1225-1228, doi: 10.1016/S0140-6736(66)90238-8.

48. Segal $B H$, Veys $P$, Malech $H$, Cowan MJ. Chronic granulomatous disease: lessons from a rare disorder. Biol Blood Marrow Transplant 2011; 17: S123-S131, doi: 10.1016/j.bbmt.2010.09.008. 